\title{
DETERMINAÇÃO DA MÁXIMA CAPACIDADE DE RETENÇÃO DE ÁGUA NO SUBSTRATO PARA PRODUÇÃO DE MUDAS DE EUCALIPTO EM VIVEIRO
}

\author{
Sandro Dan Tatagiba ${ }^{1 *}$, Talita Miranda Teixeira Xavier ${ }^{1}$, Herbert Torres $^{2}$, \\ José Eduardo Macedo Pezzopane ${ }^{3}$, Roberto Avelino Cecílio ${ }^{4}$, Sidney Sará Zanetti ${ }^{3}$ \\ ${ }^{1 *}$ Universidade Federal do Espírito Santo, Programa de Pós-Graduação em Ciências Florestais, Jerônimo Monteiro, Espírito Santo, \\ Brasil - sandrodantatagiba@yahoo.com.br; talitamtx@yahoo.com.br \\ ${ }^{2}$ Centro Universitário São Camilo, Cachoeiro de Itapemirim, Espírito Santo, Brasil - herberttorres.agro@ gmail.com \\ ${ }^{3}$ Universidade Federal do Espírito Santo, Centro de Ciências Agrárias, Departamento de Ciências Florestais e da Madeira, Jerônimo \\ Monteiro, Espírito Santo, Brasil - pezzopane2007@yahoo.com.br; sidney.zanetti@ufes.br \\ ${ }^{4}$ Universidade Federal do Espírito Santo, Departamento de Engenharia Florestal, Jerônimo Monteiro, Espírito Santo, Brasil - \\ roberto.cecilio@ufes.br
}

Recebido para publicação: 21/10/2014 - Aceito para publicação: 24/09/2015

\begin{abstract}
Resumo
A escassez de informações referentes ao consumo hídrico de mudas de espécies florestais freqüentemente dificulta o planejamento da irrigação em viveiros comerciais, levando muitas vezes, a adoção de medidas ineficientes de manejo, provocando perda no padrão de qualidade das mudas. Dessa forma, procurou-se neste trabalho investigar a máxima capacidade de retenção de água (MCRA) no substrato em que as mudas de eucalipto podem ser submetidas e determinar o coeficiente de cultivo $\left(\mathrm{K}_{\mathrm{c}}\right)$ para o clone híbrido de E. urophylla x E. grandis. O estudo foi realizado em casa de vegetação, localizada na área experimental do Programa de Pós-Graduação em Ciências Florestais vinculado ao Centro de Ciências Agrárias da Universidade Federal do Espírito Santo (CCA-UFES) no município de Alegre, ES, montado num delineamento inteiramente casualizado, com cinco tratamentos de disponibilidade hídrica no substrato (90, 80, 70, 60 e 50\% da MCRA), com quatro repetições. De acordo com os resultados obtidos, verificou-se que a disponibilidade hídrica no substrato de $70 \%$ da MCRA pode ser utilizada para a produção de mudas clonais de eucalipto, sem afetar o crescimento e o padrão de qualidade. $\mathrm{O} \mathrm{K}_{\mathrm{c}}$ estimado para as mudas de eucalipto em condições de viveiro foi de 1,25.

Palavras-chave: Coeficiente de cultivo; manejo de irrigação; Eucalyptus urophylla $\mathrm{x}$ E. grandis.
\end{abstract}

\begin{abstract}
Determination of maximum capacity of water retention in substrate for production plants in Eucalyptus nursery. The scarcity of information regarding water consumption of seedlings of forest species often complicates the planning of irrigation in commercial nurseries, often leading the adoption of inefficient management measures, causing loss in the quality of seedlings. Thus, this study sought to investigate the capacity of water retention in the substrate in which the eucalyptus seedlings can be submitted and determine the crop coefficient $\left(\mathrm{K}_{\mathrm{c}}\right)$ for the hybrid clone of $E$. urophylla $x E$. grandis. The study was conducted in a greenhouse located in the experimental area of the Post-Graduation of Forest Sciences bound to the Center for Agrarian Sciences, Federal University of Espírito Santo in the city of Alegre, ES, built in a completely randomized design with five treatments of water availability in the substrate (90, 80, 70, 60 and 50\% of MCRA) and four replications. According to the results, it was found that water availability in the substrate MCRA of the $70 \%$ can be used for the production of minicutting, without affecting standards of growth and quality. The Kc for eucalyptus seedlings in nursery conditions was 1.25.

Keywords: Coefficient of cultivation; irrigation management; Eucalyptus urophylla $x$ E. grandis.
\end{abstract}

\section{INTRODUÇÃO}

$\mathrm{O}$ viveiro destinado à produção de mudas de espécies florestais é considerado a base do processo produtivo florestal, sendo responsável pelo abastecimento de mudas para implantação de povoamentos, recuperação de áreas degradadas, arborização urbana e de parques, entre outras finalidades (VIANI; RODRIGUES, 2007; BIONDI; LEAL, 2009). Em grande parte dos viveiros comerciais o manejo da

FLORESTA, Curitiba, PR, v. 45, n. 4, p. 745 - 754 , out. / dez. 2015.

Dan Tatagiba, S. et al.

ISSN eletrônico 1982-4688 / ISSN impresso 0015-3826 
irrigação é realizado de forma subjetiva, embasado, na maioria das vezes, por observações visuais do estado de turgidez das folhas. De maneira geral, realizam-se irrigações com alta frequiência a fim de evitar danos causados pelo estresse hídrico as mudas, promovendo na maioria das vezes uma irrigação excessiva, o que pode trazer problemas fitossanitários e de ordem econômica (LOPES et al., 2009; RODRIGUES et al., 2011). Por outro lado, a falta de água limita o crescimento e o desenvolvimento das mudas (TAIZ; ZEIGER, 2013), reduzindo o vigor e o padrão de qualidade. Trabalhos realizados com mudas de eucalipto em fase inicial de crescimento demonstram redução significativa de biomassa quando submetidos à deficiência hídrica (MARCHANT et al., 2007; TATAGIBA et al., 2007; LOPES et al., 2011; KLIPPEL et al., 2014).

Para atender a demanda hídrica das plantas, o teor de água do solo não precisa necessariamente corresponder à capacidade de campo. A quantidade de água retida a baixas tensões pela matriz do solo pode suprir plenamente a demanda atmosférica deste que esteja acima do ponto de murcha permanente (PEREIRA et al., 2002). O conhecimento e a aplicação dessa informação em viveiros de mudas de eucalipto permite aprimorar o manejo de irrigação, reduzindo problemas fitossanitários e de desperdícios de água, além de promover melhoria no padrão de qualidade das mudas.

A evapotranspiração é um termo utilizado para descrever o processo físico-biológico de transferência de água para a atmosfera, na forma de vapor, através da evaporação da água do solo e da transpiração das plantas (PEREIRA et al., 2002). A quantidade de água evapotranspirada varia em função de fatores relacionados à planta, ao solo e ao clima, sendo que este último exerce maior influência (BERNARDO et al., 2006). A demanda evaporativa da atmosfera e a radiação solar podem determinar a magnitude da perda de água do solo e da planta, podendo ser quantificada através da evapotranspiração (SOUZA; WILHELM, 2009). Entretanto, há a necessidade de se estimar a evapotranspiração da cultura $\left(\mathrm{ET}_{\mathrm{c}}\right)$ do eucalipto. $\mathrm{A} \mathrm{ET}_{\mathrm{c}}$ representa a evapotranspiração da cultura cultivada em área extensa, isenta da ocorrência de pragas, doenças e deficiência nutricional, com disponibilidade hídrica suficiente para garantir o potencial produtivo (TEIXEIRA et al., 2003). A ET pode ser estimada de forma direta, através do balanço hídrico de água no solo, ou indireta, através do produto da evapotranspiração de referência $\left(\mathrm{ET}_{0}\right)$ pelo coeficiente de cultura $\left(\mathrm{K}_{\mathrm{c}}\right)$, sendo que este varia em função da espécie e de sua fase fenológica (ALLEN et al., 1998; OLIVEIRA et al., 2007).

No boletim sobre irrigação e drenagem, número 56, da Organização das Nações Unidas para Agricultura e Alimentação, pode-se encontrar o valor de $\mathrm{K}_{\mathrm{c}}$ para a maioria das culturas agrícolas em seus diferentes estágios de desenvolvimento (ALLEN et al., 1998). Entretanto, não há dados disponíveis para o eucalipto. A determinação do $\mathrm{K}_{\mathrm{c}}$ para locais específicos, como, em viveiros florestais, proporciona um melhor ajuste na determinação da evapotranspiração da cultura e permite aplicar o teor de água necessário com maior precisão (GONÇALVES, 2010). Dessa forma, o presente estudo teve o objetivo de investigar a máxima capacidade de retenção de água (MCRA) no substrato em que as mudas de eucalipto podem ser submetidas e determinar o coeficiente de cultivo $\left(\mathrm{K}_{\mathrm{c}}\right)$ para um clone híbrido de Eucalyptus urophylla $\mathrm{x}$ E. grandis.

\section{MATERIAL E MÉTODOS}

O experimento foi conduzido em casa de vegetação localizada na área experimental do Programa de Pós-Graduação em Produção Vegetal vinculado ao Centro de Ciências Agrárias da Universidade Federal do Espírito Santo (CCA-UFES) no município de Alegre, ES, latitude 2045' Sul, longitude 4130' Oeste e altitude de 119 m, no período de 11 de junho a 10 de agosto de 2013.

Foram utilizadas mudas do clone híbrido Eucalyptus urophylla $\mathrm{x}$ E. grandis multiplicadas em tubetes plásticos de $54 \mathrm{~cm}^{-3}$ pelo método de miniestaquia, selecionadas na fase de crescimento do viveiro, aos 35 dias de idade, mantendo a uniformidade de altura da parte aérea, diâmetro de colo e condição fitossanitária. Durante todo o período experimental as mudas ficaram suspensas em bancadas com aproximadamente $1 \mathrm{~m}$ de altura, com dimensões de $2 \mathrm{~m}$ de comprimento e $1,20 \mathrm{~m}$ de largura, acondicionadas em bandejas para receber 36 tubetes.

O substrato utilizado para o preenchimento dos tubetes foi constituído de uma mistura composta por $40 \%$ de fibra de coco, $40 \%$ de vermiculita, $20 \%$ de casca de pinus e do adubo de liberação lenta osmocote (19-06-10) na dose de $1,5 \mathrm{~kg} \mathrm{~m}^{-3}$ de substrato. Para melhor acomodação do substrato dentro dos tubetes, o preenchimento dos mesmos foi realizado com auxilio de uma mesa vibratória. As adubações de cobertura foram realizadas quinzenalmente, diluindo em $6 \mathrm{~L}$ de água, $18 \mathrm{~g}$ de cloreto de potássio e $60 \mathrm{~g}$ de sulfato de amônio, sendo aplicados $10 \mathrm{~mL}$ dessa solução por muda com auxílio de uma seringa.

Aos 35 dias após o transplante das miniestacas para os tubetes, foram iniciados os tratamentos de disponibilidade hídrica no substrato de 90, 80, 70, 60 e 50\% da máxima capacidade de retenção de água 
(MCRA), permanecendo por 60 dias, em bandejas suspensas nas bancadas no interior da casa de vegetação. A determinação da MCRA do substrato foi realizada em uma amostragem aleatória de quatro bandejas, cada uma contendo 36 tubetes. Para esse procedimento, o substrato no interior do tubete foi lentamente saturado com água através do auxílio de uma seringa, permanecendo em repouso, por um período de aproximadamente $12 \mathrm{~h}$, até constatar a interrupção da drenagem da água livre, momento este que procedeu a pesagem do substrato saturado juntamente com o tubete. Em seguida, o substrato foi levado a uma estufa de circulação forçada, com temperatura de aproximadamente $105^{\circ} \mathrm{C}$, a fim de proceder à secagem. Após $24 \mathrm{~h}$, realizou-se a pesagem do substrato seco. A determinação da MCRA do substrato foi realizada através da diferença entre a massa do substrato saturado pela massa substrato seco, descontando o valor do peso de cada tubete.

O controle da irrigação foi realizado pelo método gravimétrico (pesagem diária das unidades experimentais), considerando-se a massa do substrato e de água, conforme metodologia descrita por Freire et al. (1980), e pela reposição da água perdida por evapotranspiração. Quando o conteúdo de água do substrato atingia os níveis estabelecidos em cada fração de MCRA utilizadas como tratamentos, era realizada uma nova irrigação para aumentar a disponibilidade hídrica do substrato até a 100\% da MCRA. As irrigações foram realizadas em uma câmara montada com um sistema de microaspersão, localizada no exterior da casa de vegetação. Após a irrigação, a quantidade de água contida no substrato encontrava-se próxima à quantidade máxima de água que este consegue reter contra a ação da gravidade.

O consumo hídrico em mililitro $(\mathrm{mL})$ foi convertido em taxa de evapotranspiração da cultura $\left(\mathrm{ET}_{\mathrm{c}}\right)\left(\mathrm{mm}\right.$ dia) levando-se em consideração a área vegetada de aproximadamente $529 \mathrm{~cm}^{2}$ formada por cada unidade experimental. As estimativas da evapotranspiração de referência $\left(\mathrm{ET}_{0}\right)$ foram obtidas pelo método Pennam-Monteith (FAO 56), conforme Allen et al. (1998). A partir dos dados de evapotranspiração da cultura $\left(\mathrm{ET}_{\mathrm{c}}\right)$, referentes ao tratamento de $90 \%$ da MCRA e da evapotranspiração de referência $\left(\mathrm{ET}_{0}\right)$ no interior da casa de vegetação, calculou-se o coeficiente de cultura $\left(\mathrm{K}_{\mathrm{c}}\right)$ de acordo com a equação (ALLEN et al., 1998):

$$
\mathrm{K}_{\mathrm{c}}=\mathrm{ET}_{\mathrm{c}} / \mathrm{ET}_{0}
$$

Para obtenção das variáveis microclimáticas, foi instalada uma estação meteorológica automática (modelo CR 10, Campbell Scientific) com sistema de aquisição de dados programado para realizar leituras a cada dez segundos e armazenar os valores médios a cada 15 minutos. Na estação, estavam acoplados sensores de temperatura e a umidade relativa do ar (modelo CS 500, Vaisala), de radiação fotossinteticamente ativa (sensor quantum, modelo LI-190, LI-COR) e um piranômetro (modelo SP-Lite, Kipp \& Zonen) media a radiação solar global. O déficit de pressão de vapor do ar foi estimado de acordo com Pereira et al. (2002).

Ao final de 60 dias de experimentação foram avaliadas as características de crescimento, determinando-se: massa seca total, da haste e ramos, da folha, e raiz; área foliar, diâmetro no nível do coleto e altura total. A área foliar foi determinada através do medidor (modelo LI -3100, LI-COR). O diâmetro do coleto foi determinado com auxílio de paquímetro digital a $5 \mathrm{~cm}$ do substrato, e a altura das plantas, através de régua milimetrada. Para obtenção da massa seca, as plantas foram particionadas em folhas, ramos e haste e raiz, colocadas em sacos de papel em estufa de circulação forçada de ar em temperatura de $75^{\circ} \mathrm{C}$, até atingir peso constante.

$\mathrm{O}$ experimento foi montado num delineamento inteiramente casualizado, com cinco tratamentos de disponibilidade hídrica no substrato $(90,80,70,60$ e 50\% da MCRA) e quatro repetições. Cada unidade experimental foi constituída por uma bandeja contendo 36 mudas. Os dados experimentais foram submetidos à análise de variância, e quando significativas, as médias foram comparadas pelo teste de Tukey $(\mathrm{P} \leq 0.05)$ utilizando o software SISVAR ${ }^{\circledR}$, versão 5.1 (FERREIRA, 2011).

\section{RESULTADOS E DISCUSSÃO}

Na figura 1 estão apresentados os valores médios diários da temperatura, umidade relativa do ar, radiação fotossinteticamente ativa, déficit de pressão de vapor e da evapotranspiração de referência no interior da casa de vegetação durante o período experimental. $\mathrm{O}$ valor médio da temperatura situou em torno de $22,2{ }^{\circ} \mathrm{C}$, apresentando valores extremos de $28,6^{\circ} \mathrm{C}$ para a máxima e $15,6{ }^{\circ} \mathrm{C}$ para a mínima (Figura 1a). A amplitude térmica do centro de distribuição de origem do gênero Eucalyptus apresenta faixa de temperatura mínima nos meses mais frios em torno de 2 a $10{ }^{\circ} \mathrm{C}$ e de temperatura máxima nos meses mais quentes de $29^{\circ} \mathrm{C}$ (MESKIMEN; FRANCIS, 2006). Segundo Martins et al. (2007) a temperatura basal

FLORESTA, Curitiba, PR, v. 45, n. 4, p. 745 - 754 , out. / dez. 2015.

Dan Tatagiba, S. et al.

ISSN eletrônico 1982-4688 / ISSN impresso 0015-3826

DOI: $10.5380 /$ rf.v45i4.38334 
inferior para o desenvolvimento de mudas de Eucalyptus grandis é de $10{ }^{\circ} \mathrm{C}$ e a basal superior é de $36{ }^{\circ} \mathrm{C}$ (DYE et al., 2004), condições estas encontrada durante todo o período de experimentação.
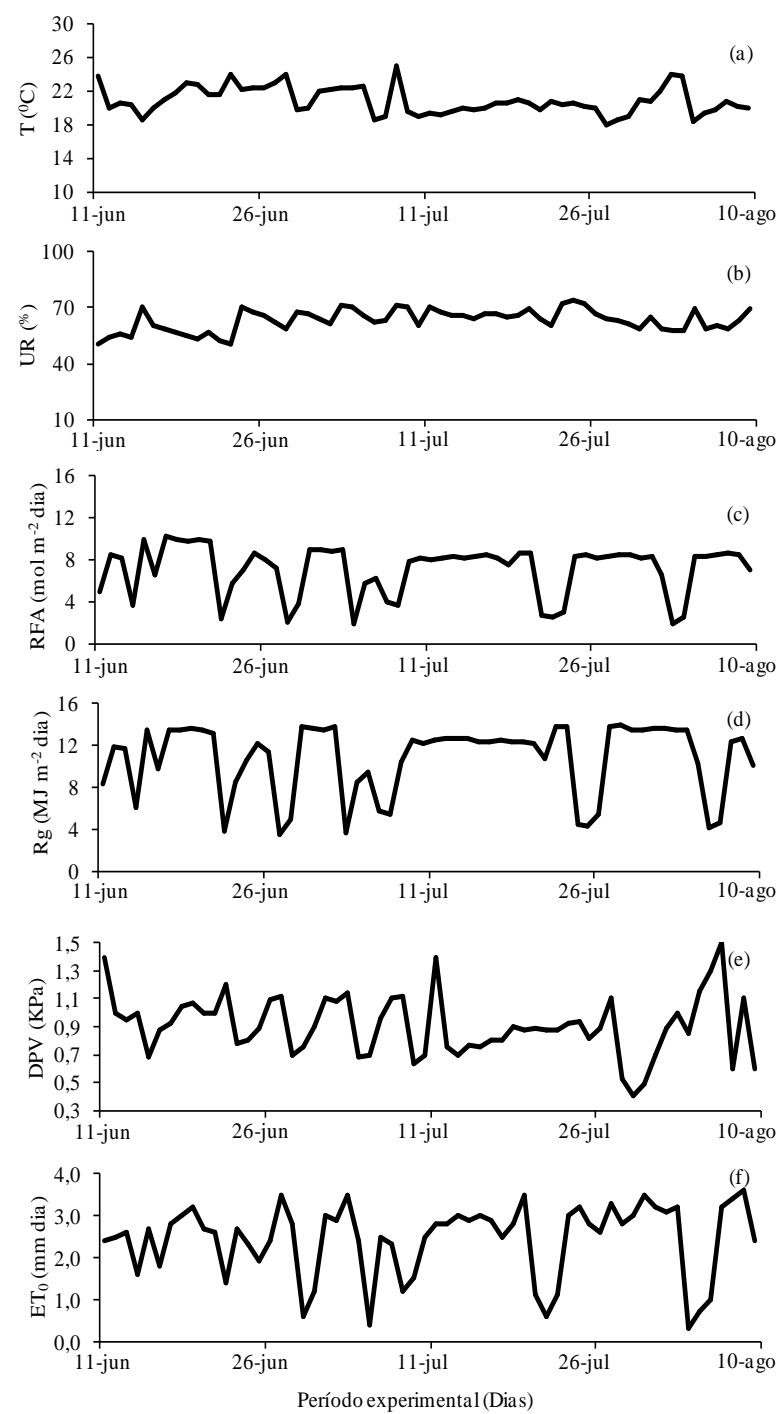

Figura 1. Valores médios da temperatura (T) (a), umidade relativa do ar (UR) (b), radiação fotossintéticamente ativa (RFA) (c), radiação global ( $\mathrm{Rg}$ ) (d). déficit de pressão de vapor (DPV) (e) e evapotranspiração de referência $\left(\mathrm{ET}_{0}\right)$ (f) no interior da casa de vegetação durante o período experimental.

Figure 1. Mean values of temperature (T) (a), relative humidity $(\mathrm{RH})(\mathrm{b})$, photosynthetic active radiation (PAR) (c), global radiation (Rg) (d). vapor pressure deficit (VPD) (e) and reference evapotranspiration $\left(\mathrm{ET}_{0}\right)(\mathrm{f})$ inside the greenhouse during the experimental period.

O valor médio registrado umidade relativa do ar foi de $64 \%$, apresentando valores extremos de máxima e mínima de 87 e $21 \%$ e, respectivamente (Figura 1b). A radiação fotossinteticamente ativa registrou média de $7,44 \mathrm{~mol} \mathrm{~m}^{-2}$ dia, com acentuadas oscilações na intensidade de $9,86 \mathrm{~mol} \mathrm{~m}^{-2}$ dia a $1,47 \mathrm{~mol} \mathrm{~m}^{-2}$ dia, devido a ocorrência de dias de céu aberto e nebulosos (Figura 1c). O comportamento da radiação global ( $\mathrm{Rg}$ ) ao longo do período de condução do experimento foi similar a RFA, apresentando valor máximo, mínimo e médio de 15,68, 3,40 e 11,48 $\mathrm{MJ} \mathrm{m}^{-2}$ dia, respectivamente (Figura 1d). Valor médio de $0,84 \mathrm{kPa}$ foi encontrado para o déficit pressão de vapor, apresentando variação entre 0,37 e 
1,39 $\mathrm{kPa}$ ao longo do período experimental (Figura 1e). Nota-se que os dias de temperatura mais elevadas coincidiram com os dias de umidade relativa mais baixa e, conseqüentemente, contribuiu para o aumento dos valores do déficit de pressão de vapor. Durante a condução do experimento a evapotranspiração de referência $\left(\mathrm{ET}_{0}\right)$ apresentou valor médio de $2,56 \mathrm{~mm}$ dia, atingindo valor máximo e mínimo de 3,73 e de $0,28 \mathrm{~mm}$ dia, respectivamente (Figura 1f).

Mudanças na disponibilidade hídrica do solo podem constituir num fator de estresse, podendo levar a redução do crescimento e da produtividade das plantas (KOZLOWSKI; PALLARDY, 1996). Percebe-se, no presente estudo, que a massa seca das mudas foi afetada pelas diferentes disponibilidades hídricas nos substratos, possibilitando diferenciar, a produtividade em cada fração de MCRA (Figura 2).
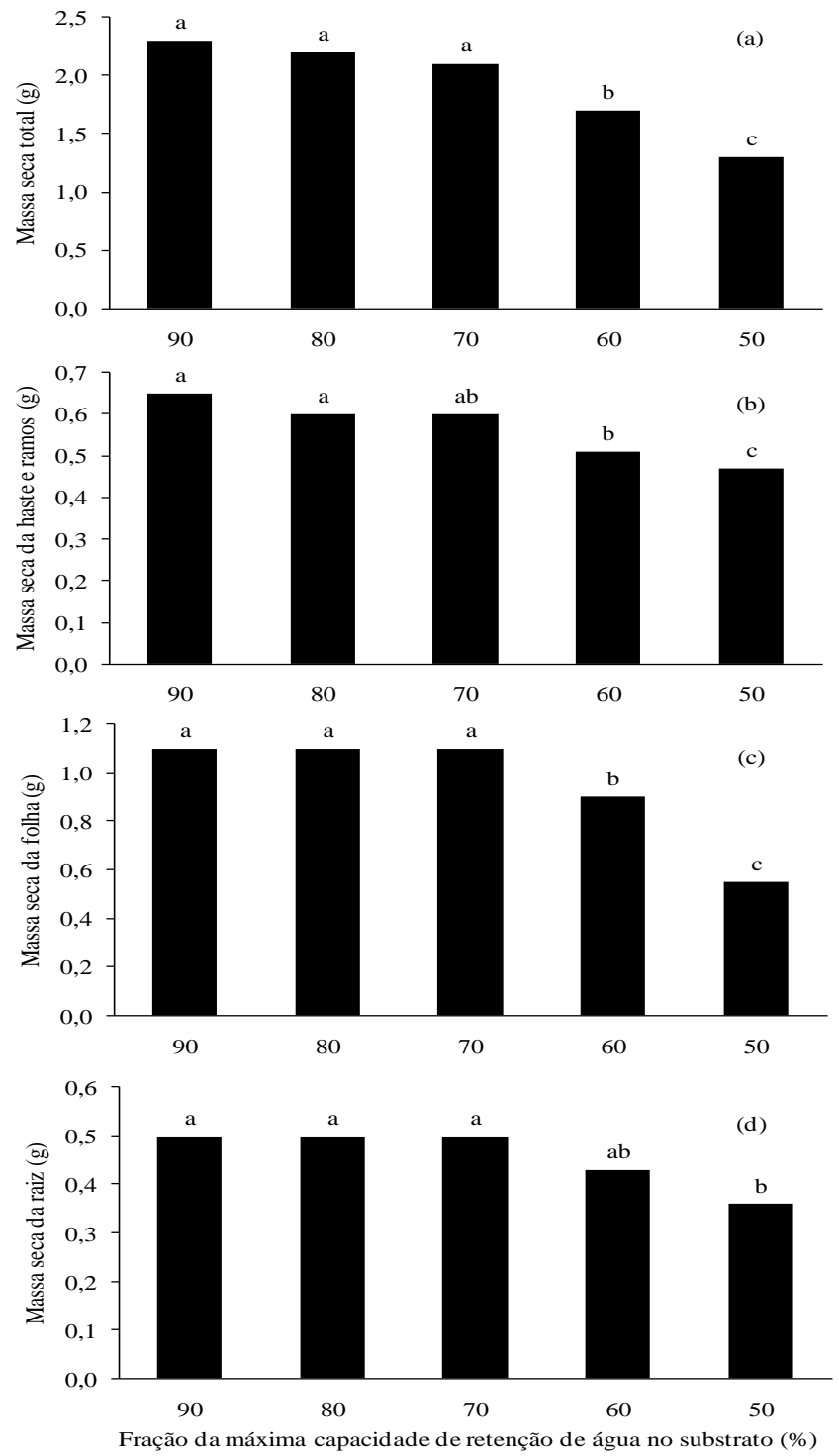

Figura 2. Massa seca total (a), da haste e ramos (b) da folha (c) e da raiz (d) em mudas clonais de Eucalyptus urophylla $x$ E. grandis submetidas a diferentes disponibilidades hídricas no substrato. Médias seguidas de mesma letra nas colunas não diferem entre si pelo teste Tukey a $5 \%$ de probabilidade.

Figure 2. Dry mass (a) of the stem and branches (b) of the sheet (c) and the root (d) in clonal Eucalyptus urophylla $\mathrm{x}$ E. grandis seedlings under different water availability in the substrate. Means followed by the same letter in columns do not differ by Tukey test at $5 \%$ probability.

FLORESTA, Curitiba, PR, v. 45, n. 4, p. 745 - 754 , out. / dez. 2015.

Dan Tatagiba, S. et al.

ISSN eletrônico 1982-4688 / ISSN impresso 0015-3826 
A massa seca total das mudas de eucalipto nos níveis de 90, 80 e 70\% da MCRA apresentaram valores significativamente superiores quando comparado com os níveis de 60 e 50\% (Figura 2a), evidenciando que a redução na disponibilidade hídrica a partir de $70 \%$ da MCRA afetou significativamente o crescimento das mudas. Estes resultados estão de acordo com os obtidos por Tatagiba et al. (2007, 2009), que estudando diferentes procedências de clones do híbrido de Eucalyptus urophylla X E. grandis submetidos a diferentes manejos hídricos, verificaram redução da massa seca total (raiz, haste e ramos, e de folhas) quando as plantas foram submetidas à umidade do solo próximo ao ponto de murcha permanente quando comparadas com as plantas crescendo na umidade próxima a capacidade de campo. Esses mesmos autores afirmam que na maioria dos casos, o estresse provocado pelo déficit hídrico, é capaz de mediar à relação de sobrevivência entre procedências de uma mesma espécie, que pode ser medida pela produtividade ou pelo processo primário de assimilação do $\mathrm{CO}_{2}$ (fotossíntese), que estão relacionadas com o crescimento geral das plantas. Lopes et al. (2005) estudando o efeito de diferentes lâminas de irrigação $(6,8,10,12$ e $14 \mathrm{~mm})$ na produção de mudas de Eucalyptus grandis, também verificaram que o crescimento foi comprometido pela redução na disponibilidade hídrica. A aplicação das frações de 60 e 50\% da MCRA resultou, respectivamente, na redução em 23 e $40 \%$ da massa seca total das plantas quando comparada com o nível de $90 \%$ da MCRA. O acúmulo de massa seca total, no final do experimento, possibilitou diferenciar a produtividade entre cada fração de disponibilidade de água aplicada, indicando tratar-se de uma característica capaz de identificar a MCRA que as mudas podem ser submetidas sem afetar o crescimento. Tendência semelhante aos valores das médias encontrados para a massa seca total foi apresentando para a massa das hastes e ramos, onde os níveis de 90, 80 e 70\% da MCRA registraram os maiores valores (Figura 2b).

A massa seca das folhas (Figura 2c), também apresentou comportamento semelhante ao observado para as médias da massa seca total, com incrementos significativos apresentados nos níveis de 90,80 e $70 \%$ da MCRA do substrato. A menor disponibilidade hídrica imposta pelos níveis de 60 e $50 \%$ da MCRA reduziu a massa seca das folhas em 24 e $47 \%$, respectivamente, em relação ao nível de $90 \%$ da MCRA. É importante observar que a massa seca das folhas foi à componente que mais contribuiu para o acúmulo de massa seca total das mudas. O incremento na matéria das folhas é um fator significativo no crescimento vegetal, uma vez que a folha é o órgão responsável pela fotossíntese, podendo favorecer uma maior produção de fotoassimilados em condições de deficiência hídrica. O crescimento do caule, por sua vez, tem sido menos estudado do que os demais órgãos das plantas, mas provavelmente, ele é afetado pelas mesmas forças que limitam o crescimento das folhas durante o estresse hídrico (TAIZ; ZEIGER, 2013).

Nos níveis de 90, 80 e 70 e 60\% de MCRA a massa seca da raiz apresentou os maiores valores, não apresentando diferenças significativas entre si (Figura 2d). Lopes et al. (2005), também verificaram aumento na massa seca da raiz em mudas de eucalipto à medida que aumentava a lâmina de irrigação. Entretanto, a redução na disponibilidade hídrica a partir de 50\% da MCRA afetou negativamente o acúmulo de massa seca da raiz.

Os resultados de massa seca obtidos sugerem deduzir que decréscimos na disponibilidade hídrica do substrato em até $70 \%$ da MCRA não afetaram significativamente o crescimento e o estabelecimento das plantas. A redução da massa seca observada nos níveis de 60 e $50 \%$ pode ser atribuída há possíveis danos causados pela menor disponibilidade hídrica no substrato, causando déficit hídrico suficiente para limitar processos fisiológicos importantes de crescimento e desenvolvimento a nível celular. A partir de $60 \%$ da MCRA, a água contida no substrato pode estar retida em tensões mais elevadas do que nos níveis acima de $70 \%$, não permitindo as plantas manterem um contínuo fluxo transpiratório no sistema soloplanta-atmosfera em dias ou horários de alta demanda evaporativa da atmosférica, levando ao fechamento dos estômatos e limitando temporariamente a assimilação do $\mathrm{CO}_{2}$ atmosférico, o que porventura, reduz a síntese de compostos orgânicos.

Na figura 3 é apresentado o crescimento das mudas de eucalipto, com relação à área foliar, diâmetro de coleto e altura da parte aérea. A área foliar nos níveis de 90, 80 e 70\% da MCRA registraram valores significativamente superiores aos demais níveis de disponibilidade hídrica. A menor disponibilidade hídrica imposta pelos níveis de 60 e 50\% da MCRA proporcionou redução média de $29 \%$ na área foliar em relação ao nível de 90\% da MCRA (Figura 3a). Entre os vários efeitos do déficit hídrico sobre o crescimento das plantas, a redução do crescimento foliar pode ser considerada uma das primeiras respostas decorrentes da redução da disponibilidade hídrica (TAIZ; ZEIGER, 2013). A área foliar é um parâmetro que pode indicar a produtividade das culturas, uma vez que a intensidade do processo 
fotossintético é proporcional à área de interceptação da energia luminosa pelas folhas (CARON et al., 2012). Em alguns trabalhos, têm sido observadas reduções da área foliar de mudas em várias espécies do gênero Eucalyptus, submetidas ao déficit hídrico, sob diferentes condições ambientais (TATAGIBA et al.; 2007, 2009; PEREIRA et al., 2010; KLIPPEL et al., 2014). No presente trabalho a redução da área foliar nas plantas sob menor disponibilidade hídrica (60 e 50\% de da MCRA) se deu tanto pela abscisão foliar quanto pela redução do tamanho das folhas. Em determinadas plantas o estresse hídrico não limitou apenas o seu tamanho, mas também o número de folhas, pois houve uma diminuição do número e do crescimento dos ramos.
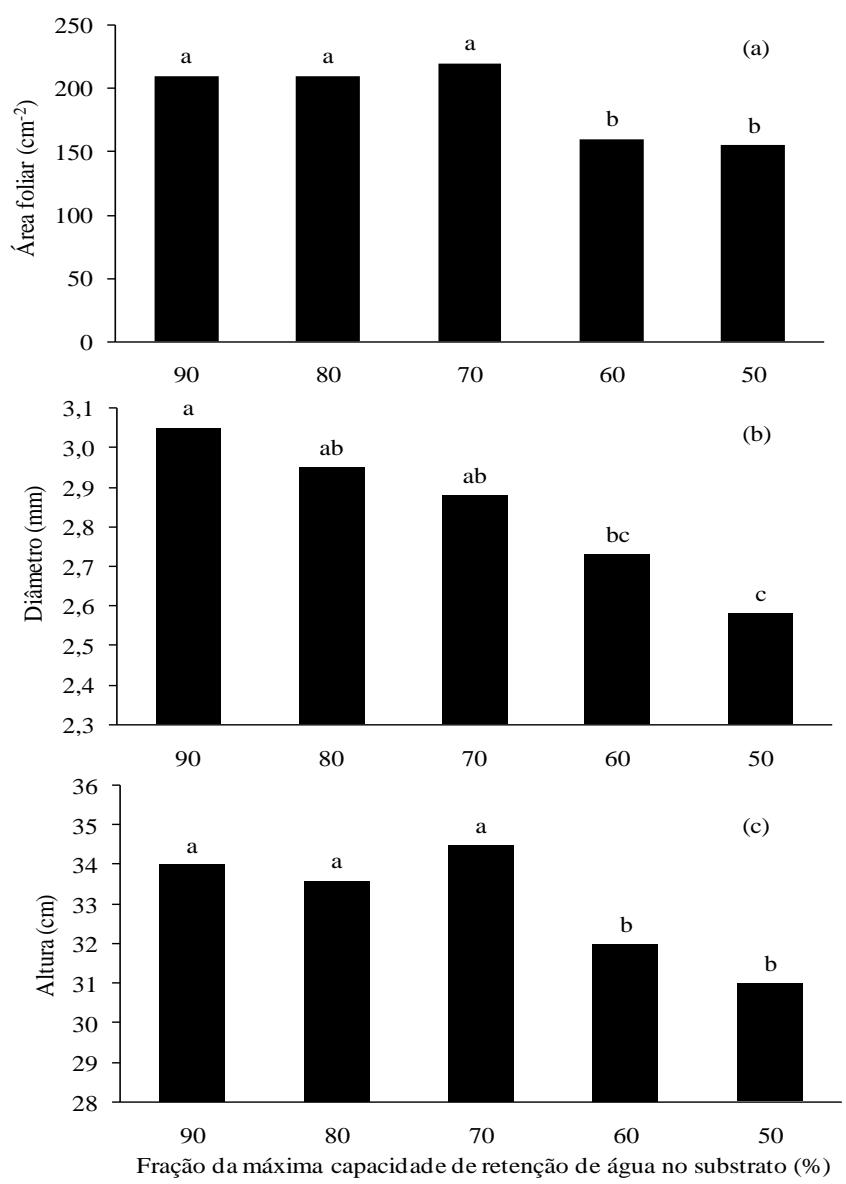

Figura 3. Área foliar (a), diâmetro do coleto (b) e altura (c) em mudas clonais de Eucalyptus urophylla $\mathrm{x}$ E. grandis submetidas a diferentes disponibilidades hídricas no substrato. Médias seguidas de mesma letra nas colunas não diferem entre si pelo teste Tukey a 5\% de probabilidade.

Figure 3. Leaf area (a), stem diameter (b) and height (c) in clonal Eucalyptus urophylla x E. grandis seedlings under different water availability in the substrate. Means followed by the same letter in columns do not differ by Tukey test at $5 \%$ probability.

Para o diâmetro no nível do coleto, valores significativamente superiores foram encontrados nos níveis de 90, 80 e 70\% da MCRA, não diferindo estatisticamente entre si. À medida que diminuía a disponibilidade hídrica do substrato, a partir de 70\% da MCRA reduções significativas do diâmetro foram encontrados (Figura 3b). Resultados similares aos encontrados para o diâmetro também foram observados para a altura das mudas, registrando valores significativamente superiores nos níveis de 90,80 e $70 \%$ da MCRA (Figura 3c). A partir de 70\% da MCRA, à medida que diminuía a disponibilidade hídrica no substrato foram encontradas reduções significativas na altura em ordem de $9,7 \%$ e $11,5 \%$ para os níveis de 60 e $50 \%$ da MCRA, respectivamente. Vellini et al. (2008), estudando o desempenho de 18 clones de

FLORESTA, Curitiba, PR, v. 45, n. 4, p. 745 - 754 , out. / dez. 2015.

Dan Tatagiba, S. et al.

ISSN eletrônico 1982-4688 / ISSN impresso 0015-3826 
Eucalyptus spp. em diferentes disponibilidades hídricas, também verificaram que a altura e o diâmetro foi reduzido pelo déficit hídrico afetando negativamente o crescimento das plantas.

Na figura 4 é apresentada a lâmina total de água consumida em cada fração da MCRA no substrato. Observa-se nos níveis de 90, 80 e 70\% da MCRA que houve consumo hídrico semelhante em cada tratamento, não oferecendo limitação de água no substrato capaz de restringir a taxa de evapotranspiração. A redução de 11 e $27 \%$ no consumo hídrico obtido nas frações de 60 e $50 \%$ da MCRA, à medida que diminuía a disponibilidade hídrica, pode ter contribuído para a retenção de água em tensões mais elevadas nas partículas do substrato, diminuindo a taxa de evapotranspiração, o que pode ter proporcionado menor crescimento das mudas.

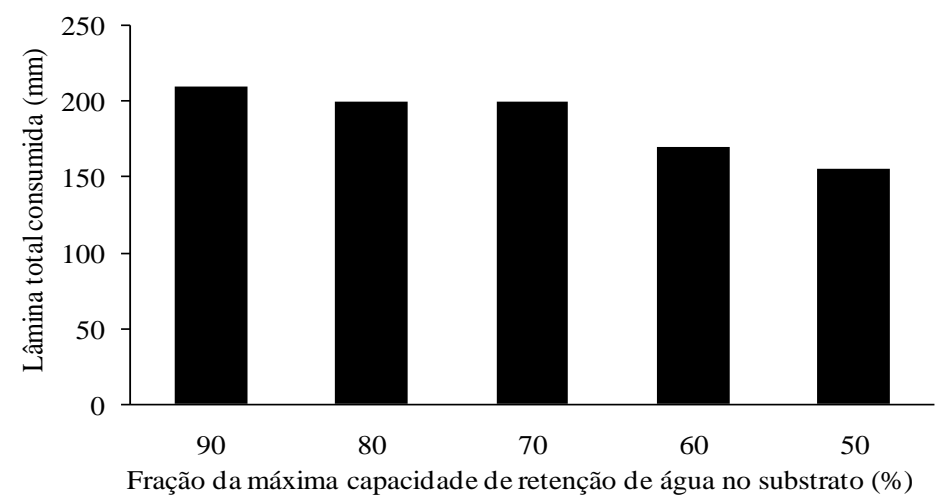

Figura 4. Lâmina total de água consumida em mudas clonais de Eucalyptus urophylla x E. grandis submetidas a diferentes disponibilidades hídricas no substrato.

Figure 4. Total water blade consumed in clonal Eucalyptus urophylla x E. grandis seedlings under different water availability in the substrate.

A evapotranspiração da cultura $\left(\mathrm{ET}_{\mathrm{c}}\right)$ do eucalipto na fase de produção de mudas no interior da casa de vegetação é apresentada na figura 5. Durante o período experimental a $\mathrm{ET}_{\mathrm{c}}$ apresentou valor médio de 3,21 mm dia, registrando valor de máxima e mínima em 4,81 e 1,28 $\mathrm{mm}$ dia, respectivamente.

De posse dos dados médios de $\mathrm{ET}_{\mathrm{c}}$ medida e $\mathrm{ET}_{0}$ estimada para as condições em casa de vegetação, determinou-se o valor médio de $\mathrm{K}_{\mathrm{c}}$ igual a 1,25 para mudas de eucalipto, utilizando os dados do nível de $90 \%$ da MCRA. Essa informação é de grande valia para estimativa do consumo hídrico de mudas de eucalipto na fase de viveiro e permite aos viveiristas otimizar o manejo de irrigação de acordo com a real necessidade hídrica da cultura.

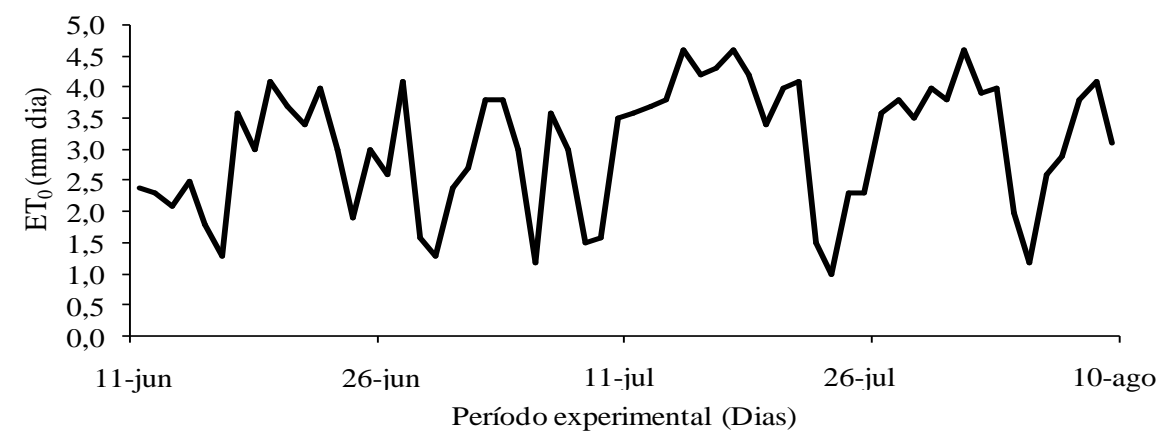

Figura 5. Evapotranspiração da cultura (ETc) em mudas clonais de Eucalyptus urophylla x E. grandis durante o período experimental.

Figure 5. Crop evapotranspiration (ETc) in clonal Eucalyptus urophylla x E. grandis seedlings during the experimental period. 


\section{CONCLUSÕES}

- A disponibilidade hídrica no substrato com 70\% da MCRA pode ser utilizada na produção de mudas clonais do híbrido Eucalyptus urophylla x E. grandis, nas condições microclimáticas do estudo, sem afetar o crescimento e o padrão de qualidade das mudas.

- $\mathrm{O} \mathrm{K}_{\mathrm{c}}$ estimado para as mudas de eucalipto em condições de viveiro foi de 1,25.

\section{REFERÊNCIAS}

ALLEN, R. G; PEREIRA, L. S.; RAES, D.; SMITH, M. Crop Evapotranspiration - Guidelines for computing crop water Requirements. Roma, 301 p. (FAO Irrigation and drainage paper 56). 1998.

BERNARDI, M. R.; SPEROTTO JUNIOR, M.; DANIEL, O.; VITORINO, A. C. T. Crescimento de mudas de Corymbia citriodora em função do uso de hidrogel e adubação. Cerne, v. 18, n. 1, p. 67 - 74 , 2012.

BERNARDO, S.; SOARES, A. A.; MANTOVANI, E. C. Manual de irrigação. $8^{\circ}$ edição. Viçosa. Editora UFV. , 2006, $625 \mathrm{p}$.

BIONDI, D.; LEAL, L. Comportamento silvicultural de espécies nativas em viveirode espera para uso potencial em arborização de ruas. Scientia Forestalis, v. 37, n. 83, p. 313 - 319, 2009.

CARON, B. O.; SOUZA, V. Q.; TREVISAN, R.; BEHLING, A.; SCHIMIDR, D.; ELOY, R. B. Eficiência de conversãp de radiação fotossinteticamente ativa interceptada em fitomassa de mudas de eucalipto. Revista Árvore, v. 36, n. 5, p. 833 - 842, 2012.

DYE, P. J.; JACOBS, S.; DREW, D. Verification of 3-PG growth and water-use predictions in twelve Eucalyptus plantation stands in Zululand, South Africa. Forest Ecology and Management, v. 193, p. $197-218,2004$.

FERREIRA, D. F. Sisvar: a computer statistical analysis system. Ciência e Agrotecnologia, v. 35, n. 6, p. 1039 - 1042, 2011.

FREIRE, J. C.; RIBEIRO, M. V. A.; BAHIA, V. G.; LOPES, A. S.; AQUINO, L. H. Respostas do milho cultivado em casa de vegetação a níveis de água em solos da região de Lavras (MG). Revista Brasileira de Ciência do Solo, v. 4, n. 1, p. 5 - 8, 1980.

GONÇALVES, F. M. Evapotranspiração e coeficiente de cultivo da cana de açúcar irrigada por gotejamento subsuperficial. 2010, 65 p. Dissertação (Mestrado em Engenharia Agrícola). Centro de Ciências Agrárias, Uversidade Federal do Ceára, 2010.

KLIPPEL, V. H.; PEZZOPANE, J. E. M.; PEZZOPANE, J. R. M.; TOLEDO, J. V. Impacto da deficiência hídrica no crescimento incial de eucalipto. Revista Científica Eletrônica de Engenharia Florestal, v. 23, n. 1, p. 48 - 59, 2014.

KOSLOWSKI, T. T.; PALLARDY, S. G. Physiology of woody plants. 2. ed. San Diego: [s.n.], 1996. $411 \mathrm{p}$.

MARTINS, F. B.; SILVA, J. C.; STERCK, N. A. Estimativa da temperatura-base para emissão de folhas e do filocrono em duas espécies de eucalipto na fase de muda. Revista Árvore, v. 31, p. 373 - 381, 2007.

MESKIMEN, G.; FRANCIS, J. K. Eucalyptus grandis Hill (ex. Maiden) Rose gum Eucalyptus. Disponível em: <http://www.na.fs.fed.us/Spfo/pubs/silvics_manual/volume_2/eucalyptus/grandis.htm> 10 Jun. 2014.

LOPES, J. L. W.; SAAD, J. C. C.; GUERRINI, I. A.; LOPES, C. F. Influência dos fatores bióticos e abióticos na sobrevivência deeucalipto em função do solo e do manejo de viveiro. Biotemas, v. 22, n. 2 , p. $29-38,2009$. 
LOPES, J. L. W.; GUERRINI, I. A.; SAAD, J. C. C. Efeito de lâminas de irrigação de irrigação na produção de mudas de Eucalyptus grandis W. (HILL ex. MAIDEN) em substrato de fibra de coco. Irriga, Botucatu, v. 10, n. 2, p. 123 - 134, 2005.

OLIVEIRA, L. F. C.; OLIVEIRA, R. Z.; BORGES, L. B.; WEHR, R. B. Coeficiente de cultura e relações hídricas do cafeeiro, cultivar catucaí, sob dois sistemas de manejo de irrigação. Pesquisa Agropecuária Tropical, v. 37, n. 3, p. 154 - 162, 2007.

PEREIRA, A. R.; ANGELOCCI, L. R.; SENTELHAS, P. C. Agrometeorologia: fundamentos e aplicações práticas. Guaíba: ed. Agropecuária, 2002. 478 p.

PEREIRA, M. R. R.; SOUZA, G. S. F.; RODRIGUES, A. C. P.; FILHO, A. L. M.; KLAR, A. E. Análise de crescimento em clones de eucalipto submetidos a estresse hídrico. Irriga, v. 15, n. 1, p. 98 - 110, 2010

MERCHANT, A.; CALLISTER, A.; ARNDT S.; TAUSZ, M.; ADAMS, M. Contrasting physiological response of six Eucalyptus species to water deficit. Annals of Botany, v. 100, n. 7, p. 1507 - 1515, 2007.

RODRIGUES, S. B. S.; MANTOVANI, E. C.; OliVEIRA, R. A.; PAIVA, H. N.; ALVES, M. E. B. Necessidades hídricas de mudas de eucalipto na região centro-oeste de Minas Gerais. Irriga, v. 16, n. 2, p. 212 - 223, 2011.

SASSE, J.; SANDS, R. Comparative responses of cottungs and seedlings of Eucalyptus globulus to water stress. Tree Physiology, Victoria, v. 16, n. 1, p. 287 - 294, 1996.

SOUZA, P. C. T.; WILHELM, V. E. Uma revisão bibliográfica dos modelos agrometeorológico. Tuiuti: Ciência e Cultura, n. 42, p. 141 - 150, Curitiba, 2009.

TAIZ, L.; ZEIGER, E. Fisiologia vegetal. 5. ed. Porto Alegre: Artmed, 2013, 954 p.

TATAGIBA, S. D.; PEZZOPANE, J. E. M.; REIS, E. F.; PENCHEL, R. M. Desempenho de clones de eucalipto em resposta a disponibilidade de água no substrato. Engenharia na Agricultura, v. 17, n. 3, p. 179 - 189, 2009.

TATAGIBA, S. D.; PEZZOPANE. J. E. M.; REIS, E. F.; DARDENGO, M. C. J. D.; EFGEN, T. A. M. Comportamento fisiológico de dois clones de Eucalyptus na época seca e chuvosa. Cerne, v. 13, n. 2, p. $149-159,2007$.

TEXEIRA, A. H.; BASSOI, L. H.; REIS, V. C. S.; SILVA, T. G. F.; FERREIRA, M. N. L.; MAIA, J. L. T. Estimativa do consumo hídrico da goiabeira, utilizando estações agrometeorológicas automática e convencional. Revista Brasileira de Fruticultura. Jaboticabal, v. 25, n. 3, p. 457 - 460, 2003.

VELlini, A. L. T. T.; PAUlA, N. F. de; ALVES, P. L. C. A.; PAVANI, L. C.; BONINE, C. A. V.; SCARPINATI, E. A.; PAULA, R. C. Respostas fisiológicas de diferentes clones de eucalipto sob diferentes regimes de irrigação. Revista Árvore, Viçosa, v. 32, p. 651 - 663, 2008.

VIANI, R. A. G.; RODRIGUES, R. R. Sobrevivência em viveiro de mudas de espécies nativas retiradas da regeneração natural de remanescente florestal. Pesquisa Agropecuária Brasileira, v. 42, n. 8, p. 1067 - 1075, 2007. 